Reseña

Cuestiones de Filosofía

ISSN: 0123-5095

E-ISSN: 2389-9441

Vol. $4-\mathrm{N}^{\mathrm{o}} 23$

Julio - diciembre, año 2018

pp. 203-208

\title{
Foucault, M. (2018). Histoire de la sexualité: Les aveux de la chair (Vol. IV). Paris: Gallimard.
}

\author{
History of sexuality: Confessions of the flesh \\ (Vol. IV). Paris: Gallimard.
}

Juan Guillermo Díaz Bernal ${ }^{1}$

Universidad Pedagógica y Tecnológica de Colombia

1 Doctor en Educación por la Universidade Federal de Uberlândia (Brasil). Profesor asociado de la Escuela de Filosofía en la Universidad Pedagógica y Tecnológica de Colombia (UPTC). Esta reseña crítica se elabora en el marco del proyecto "Experiencia, ética y sujeto en el último Foucault", financiado por la Dirección de Investigaciones de la UPTC, código SGI - 2190. Correo electrónico: juan.diaz@uptc.edu.co 
Autor: Michel Foucault (1926-1984)

Editorial: Gallimard

Año: 2018

\section{Situación del texto}

Antes de partir a Polonia, en septiembre de 1982, Michel Foucault recomienda en su testamento que no se realicen publicaciones póstumas de sus obras. En 2018, la editorial Gallimard incumple el deseo del filósofo al publicar Las confesiones de la carne, el último volumen de Historia de la sexualidad. Su edición ha corrido por cuenta de Frédéric Gros, reconocido también por algunas de las ediciones de los cursos del Collège de France.

El plan sobre la "Historia de la sexualidad" de Foucault fue realizado desde 1976, con la aparición del primer volumen subtitulado La voluntad de saber. Al momento de su publicación, se anunciaron seis volúmenes que terminan en la modernidad; sin embargo, la investigación foucaultiana sobre la sexualidad incluye primero el periodo greco-romano y finaliza con el análisis de la Edad Media. Ahora bien, la intención de ofrecer una genealogía, a través de las problematizaciones que constituyen el sujeto, se extiende a través de diferentes discursos y dispositivos como la ontología del presente.

De acuerdo con F. Gros (2018), el libro en cuestión cierra el proyecto que indica cómo la redacción definitiva de Las confesiones de la carne se sitúa entre 1981 y 1982, esto es, paralelo al curso Subjetivite et verite, inédito en español hasta el momento. Lo anterior arroja como consecuencia la perfecta correspondencia entre el Foucault autor y el Foucault profesor. Es sabido, además, que nuestro filósofo acostumbraba a reelaborar los textos y examinarlos varias veces antes de su publicación (2014). Cabe recordar que gracias a Paul Veyne se publican finalmente los volúmenes II y III de Historia de la sexualidad, titulados El uso de los placeres y La inquietud de sí, los cuales versan sobre la antigüedad. Ambos salen a la luz antes de muerte de Foucault, acaecida el 25 de junio de 1984. Siguiendo la Cronología de Defert (1994), el manuscrito sobre Las confesiones de la carne fue terminado en abril de 1984, mas nunca fue autorizada su edición y posterior publicación.

Desde hace varias décadas se sabe de la existencia de Las confesiones de la carne, ya que ha estado disponible, en parte, por los archivos de Michel Foucault; por lo tanto, hay algunos informes resumidos. Además, se sabe del contenido de la obra, pues desde 1994 se tiene acceso a los Dits et Écrits que contienen casi todos los textos, entrevistas e intervenciones con el 
nombre del autor, así como los cursos impartidos en el Collège de France. Consecuentemente, cuesta entender la diferencia entre la publicación de un curso que fue pronunciado públicamente y -que estaría más en la línea del testamento de Foucault- que la publicación de un libro de investigación, al cual le dedicó el final de su vida.

Con este libro, los estudios foucaultianos tienen un documento de referencia sobre el cristianismo, un punto clave para las investigaciones en torno al "último Foucault". En un trabajo cauteloso de edición, Frédéric Gros aclara y propone algunos nexos que aparecen en una lectura de un trabajo "incompleto", o mejor con algunas lagunas (a veces importantes) como párrafos faltantes. Sin embargo, esto no resulta extraño, dado que no es algo que vaya más allá de lo acostumbrado por el Foucault profesor de los cursos del Collège de France. En todo caso, la ausencia en el libro de una introducción y una conclusión arroja un sin sabor, lo cual nos lleva a preguntar si eso mismo quería el Foucault autor.

En la "Advertencia" que realiza Frédéric Gros acerca del contenido de los textos sobre la Alta Edad Media abordados en el libro, se resalta que son utilizados especialmente en diversas invenciones y textos publicados en el periodo de elaboración. Asimismo, hay que anotar que existe una diferencia significativa en las actividades investigativas de Foucault, pues marca un énfasis en el periodo de la antigüedad tardía (siglos II y IV) que caracterizó su curso Del gobierno de los vivos, el cual comienza su preparación de lecturas sobre la exemologese, que curiosamente será parte de los anexos del libro como temática.

\section{Estructura}

\subsection{Prácticas cristianas}

El libro parte como investigación desde la "formación de una nueva experiencia”, para usar el mismo título de la primera parte que Foucault centra en la era cristiana. Es evidente que la primera parte trata de unas autotecnologías o tecnologías de sí que se usaron durante ese periodo. También cabe anotar que la problematización aquí se centra en el "acto sexual" en el entorno matrimonial y se retoman dos de las grandes técnicas de subjetivación del cristianismo, a saber: el bautizo y la penitencia. Es así como Foucault (2018) recoge del Pedagogo de Clemente de Alejandría las tradiciones griegas y cristianas al respecto, siendo pertinente señalar cómo se introduce una recalificación de la posición metafísica innovadora del individuo dentro 
de la tradición cristiana. La experiencia con el "yo" cristiano toma relevancia como voluntad carnal que lo mueve como llama y es allí cuando emerge el término "carne", pues es una experiencia posible gracias a las técnicas de auto-evocación estudiadas en detalle.

Para saber si lo divino participa en la acción individual, se hace necesaria una producción de verdad por parte del sujeto, la cual parece estar en el corazón de la concepción cristiana de la subjetividad, incluso en los tiempos modernos. Es aquí donde Foucault coloca la gran diferencia entre las formas de liderazgo de la conciencia antigua y cristiana: mientras que una era puntual, la otra es total, mientras que una era pedagógica, la otra es disciplinaria. Por lo tanto, el problema se desplaza de cómo usar la razón adecuadamente a si la razón es lo que dice ser. En otras palabras, ya no es el objeto del pensamiento, sino el sujeto que ahora plantea un problema.

\subsection{La virginidad según el cristianismo}

La segunda parte permite establecer la preocupación cristiana por la virginidad. En el cristianismo primitivo la problematización sobre la virginidad se plantea, por un lado, dentro de la iglesia y en contra de las corrientes que abogan por la abstinencia radical; por otro lado, exteriormente a una relación con las mujeres.

Además, existen demostraciones de "prácticas paganas" que conducen al desarrollo del concepto de continencia entendido como forma de vida. Es así como este fenómeno no es reconocido como marco legal negativo, sino como una técnica de sí (positiva). En ese sentido, la continencia es, por lo tanto, una promesa de la nueva ontología del individuo. Simultáneamente, esta concepción requiere el desarrollo de una técnica de dirección de la conciencia que tendrá como objeto la voluntad del alma, ya que es sólo en el juego del alma consigo misma enmarcada como castidad.

\subsection{El matrimonio como finalidad teológico-ética}

La tercera y última parte del libro se dedica a la cuestión del matrimonio, a sus consideraciones preliminares y su importancia. Resulta que la pareja matrimonial ahora recuperará una posición original, ya que forma el elemento de relevo entre las técnicas de sí cristianas y la dirección política de los individuos (tecnología de gobierno). Foucault lo demuestra a través del análisis a uno de los Padres de la Iglesia llamado Casiano, para quien el matrimonio tiene una doble función: por un lado, es el signo de la creación 
divina en el linaje de Adán y Eva; por otro lado, es la reproducción en miniatura del vínculo entre Cristo y la Iglesia.

Finalmente, los últimos capítulos tratan sobre algunos postulados de San Agustín, quien provocó cambios importantes para el advenimiento del cristianismo y que, eventualmente, llevaron a la producción y experiencia del sujeto cristiano. San Agustín reescribe la cuestión de los vínculos entre el matrimonio y la virginidad, con lo que propone una teoría original del tema del deseo.

El análisis de los textos agustinianos de Foucault es fascinante, puesto que demuestra que el problema aparentemente moderno de una doble constitución legal del tema se remonta a este autor que inauguró la Edad Media. De hecho, Foucault primero muestra cómo el matrimonio es valorado por San Agustín, en particular por el papel central que desempeña en la reproducción de la comunidad cristiana.

La cuestión de la continencia impide que el matrimonio sea un simple problema legal, ya que también es un vector de la comunión de las voluntades y la salvación de los socios involucrados en ella. Esta forma de plantear el problema, además de fomentar el desarrollo de la "jurisprudencia de las relaciones sexuales entre cónyuges" (Foucault, 2018, p. 322), hace que el tema de la libido parezca ser un tema central. En otras palabras, "la definición del vínculo del matrimonio y las reglas de vida que deben caracterizar el estado civil, según Agustín, no se puede completar sin una teoría de la libido" (Foucault, 2018, p. 324). De hecho, San Agustín abandona la tradición ética de los no excesos en favor de una problematización de la libido que resulta ser tan importante para el problema de la ética en particular como para la concepción del sujeto en general.

Según Foucault, la gran novedad de San Agustín fue haber reflejado estos problemas no en la antigua perspectiva del autocontrol para evitar la contaminación y el exceso, sino el colocarlos en "un sistema de referencias legales" (2018, p. 351), o sea, a través del problema de la voluntad en su relación con el otro. En una palabra, ahora es necesario "pensar simultáneamente y en una forma el sujeto del deseo y el sujeto del derecho" (2018, p. 352).

Hasta ese momento, el problema se había planteado a través de la posible adopción del objeto del deseo por parte de la voluntad. Sin embargo, ahora se tratará de determinar si la voluntad adopta su propio movimiento, si constituye una voluntad concupiscente, si el sujeto se decide constituir "como un sujeto 
que desea" (2018, p. 355). La elección realizada luego por el testamento permite simultáneamente "asignar el tema de la concupiscencia como un tema de derecho" (2018, p. 355). En este orden de ideas, el lugar del problema ya no es una práctica reguladora del placer-como aconteció en la antigüedad-sino el deseo que anima a un sujeto y que también apela a una actividad. De lo que se trata es de la veracidad de lo que mueve el alma sólo a una jurisdicción. El punto culminante es esta "analítica del tema de la concupiscencia" (2018, p. 361) que constituye el corazón de las prácticas de sí hasta hoy.

\section{Conclusión}

En suma, la publicación de este último libro de Michel Foucault arroja luz sobre la última zona de sombras que persistió en los estudios foucaultianos, lo que permitió a la investigación internacional acceder finalmente a este último gran texto inédito del filósofo (Díaz, 2017). Pero el interés principal radica ciertamente en el hecho de que ahora tenemos la versión final que Foucault había decidido dar a su análisis e interpretación de los textos de los padres de la Iglesia. A la luz de las obras e intervenciones del mismo período ya publicadas, esto plantea una serie de preguntas interesantes y, sobre todo, las que apuntan al análisis de este momento de formación del sujeto cristiano de alrededor del siglo IV, que constituye el punto clave en el que se basa nuestro "yo" hasta hoy.

\section{Referencias}

Defert, D. (1994). Chronologie. M. Foucault. Dits et Écrits: 1954-1969. Vol. I (pp. 13-64). Paris: Gallimard.

Díaz, J. (2017). Gubernamentalidad y cristianismo en Michel Foucault. O. Pulido y O. Espinel (Eds.), Formas y expresiones metodológicas en el último Foucault (pp. 215- 240). Tunja: Universidad Pedagógica y Tecnológica de Colombia.

Foucault, M. (2014). Subjectivité et vérité: Cours au Collège de France (19801981). Paris: Seuil/Gallimard.

Foucault, M. (2018). Histoire de la sexualité: Les aveux de la chair (Vol. IV). Paris: Gallimard.

Gros, F. (2018). Avertissement. M. Foucault. Histoire de la sexualité: Les aveux de la chair (Vol. IV) (pp. 6-18). Paris: Gallimard. 